\title{
Stark broadening of solar Mg I lines
}

\author{
M.S. Dimitrijević ${ }^{1}$ and S. Sahal-Bréchot ${ }^{2}$ \\ 1 Astronomical Observatory, Volgina 7, 11050 Beograd, Yugoslavia \\ 2 Laboratoire "Astrophysique, Atomes et Molécules", Département Atomes et Molécules en Astrophysique Unité \\ associée au CNRS No. 812, observatoire de Paris-Meudon, 92190 Meudon, France
}

Received July 31; accepted September 27, 1995

\begin{abstract}
Using a semiclassical approach, we have calculated electron-, proton-, Mg II-, Si II-, Fe II-, and Ar II- impact line widths and shifts for $267 \mathrm{Mg}$ I multiplets, in order to provide the needed Stark broadening parameters for all important perturbers for investigation of Solar and laboratory plasma. An analysis of Solar Rydberg lines in the far infrared spectrum has been performed as well.
\end{abstract}

Key words: lines: profile-atomic and molecular data - Sun: photosphere — Sun: chromosphere

\section{Introduction}

Lines of neutral magnesium are present in the Solar spectrum and the corresponding Stark broadening parameters are of interest for their analysis as well as for the diagnostic of Solar plasma. Especially the infrared lines of $\mathrm{Mg}$ I have been observed in the Solar spectrum at Kitt Peak and during the Atmos experiment on Spacelab (Brault \& Noyes 1983; Chang \& Noyes 1983; Farmer \& Norton 1989; Jefferies 1991). Other observations of such lines have been described by Deming et al. 1988, 1991; Glenar et al. 1988). Due to the suitability of these lines for the solar atmosphere investigations (see e.g. Van Regemorter \& Hoang-Binh 1993) and to the fact that with the increase of the principal quantum number increases the importance of Stark broadening as well, the corresponding Stark widths and shifts are of importance for the structure of the Solar atmosphere research and solar plasma diagnostic (see e.g. Chang et al. 1991; Carlson et al. 1992). Stark broadening data for Mg I lines are also of interest for laboratory plasma research and have been investigated experimentally (Helbig \& Kusch 1972; Kusch \& Schweicker 1976; Goldbach et al. 1982) and theoretically (Benett \& Griem 1971; Griem 1974; Brissaud et al. 1976; Dimitrijević \& Konjević 1986; Marasinghe et al. 1986; Regemorter \& Hoang Binh 1993; Dimitrijević \& Sahal-Bréchot 1995).

By using the semiclassical-perturbation formalism (Sahal-Bréchot 1969a, b), electron-, proton-, and ionized argon-impact line widths and shifts for $99 \mathrm{Mg}$ I multiplets

Send offprint requests to: M.S. Dimitrijević

* Tables 1-3 are only available in electronic form via anonymous ftp 130.79 .128 .5 have been published recently at an electron density of $10^{15} \mathrm{~cm}^{-3}$, in order to provide Stark broadening data needed for laboratory plasma research and diagnostic (Dimitrijević \& Sahal-Bréchot 1995). Using the same semiclassical approach, we have calculated here electron-, proton-, Mg II-, Si II-, Fe II-, and Ar II-impact line widths and shifts for $267 \mathrm{Mg}$ I multiplets at an electron density of $10^{11} \mathrm{~cm}^{-3}$, in order to provide the needed Stark broadening parameters for all important perturbers in the investigation and modelling of Solar plasma. A summary of the formalism is given in Dimitrijević et al. (1991).

\section{Results and discussion}

Energy levels for Mg I lines have been taken from Bashkin $\&$ Stoner (1975). For high $n$ and $\ell$, needed atomic energy levels not existing in Bashkin \& Stoner, have been calculated by using the theoretical polarization formula of Waller (1926) (see e.g. Regemorter \& Hoang Binh 1993 or Edlen 1964) valid for the angular momenta $\ell$ larger than 3. Oscillator strengths have been calculated by using the method of Bates \& Damgaard (1949) and the tables of Oertel \& Shomo (1968). For higher levels, the method described by Regemorter et al. (1979) has been used. In order to check the applicability of Bates \& Damgaard's (1949) method for the calculation of oscillator strengths within the Coulomb approximation, line width calculations with line strengths from TOP base (the complete package of the opacity project (OP) data with the database management system is usually referred to as TOP base, see Butler et al. (1993) and Cunto et al. (1993)) have been performed at an electron density of $10^{12} \mathrm{~cm}^{-3}$ and $T=$ $5000 \mathrm{~K}$. For the $3 \mathrm{~s}^{2}{ }^{1} \mathrm{~S}-3 \mathrm{~s} 3 \mathrm{p}^{1} \mathrm{P}^{0}$ resonance line the 
full width with Bates \& Damgaard line strengths is $0.6310^{-6} \AA$ and with TOP base line strengths $0.5210^{-6}$ $\AA$. For $6 \mathrm{~s}^{3} \mathrm{~S}-6 \mathrm{p}^{3} \mathrm{P}^{0}$ infrared line the full halfwidth is 0.162 $\AA$ in both cases. One can see that for transitions between low levels small differences exist. However, for lines that are of interest for solar infrared astrophysics, corresponding to transitions between high levels, the use of Bates \& Damgaard oscillator strengths is sufficient for line widths. In addition to electron-impact full halfwidths and shifts, Stark-broadening parameters due to proton-, Mg II-, Si IIand Fe II- impacts have been calculated in order to provide an as much as possible complete set of Stark broadening data for Solar plasma research. Moreover, Starkbroadening parameters due to Ar II-impacts have been calculated as well, since argon is usually used as a carrier gas for experimental determination of Mg I Stark widths and shifts.

Our results for Stark broadening parameters due to e-, p-, and Ar II-impacts for $267 \mathrm{Mg}$ I multiplets are shown in Table 1 (accessible only in electronic form), and due to Si II-, Fe II-, and Mg II-impacts in Table 2 (accessible only in electronic form) for perturber density of $10^{11} \mathrm{~cm}^{-3}$ and temperatures $T=2.500-50.000 \mathrm{~K}$. Stark broadening parameters due to e-, p-, and Ar II-impacts for perturber densities $10^{15} \mathrm{~cm}^{-3}-10^{19} \mathrm{~cm}^{-3}$ are shown in Table 3 (accessible only in electronic form). We also specify a parameter c (Dimitrijević \& Sahal-Bréchot 1984), which gives an estimate for the maximum perturber density for which the line may be treated as isolated when it is divided by the corresponding electron-impact full width at half maximum. For each value given in Table 1 , the collision volume $(V)$ multiplied by the perturber density $(N)$ is much less than one and the impact approximation is valid (Sahal-Bréchot 1969a, b). Values for $N V>0.5$ are not given and values for $0.1<N V \leq 0.5$ are denoted by an asterisk. When the impact approximation is not valid, the ion broadening contribution may be estimated by using quasistatic estimations (Sahal-Bréchot 1991; Griem 1974). The accuracy of the results obtained decreases when broadening by ion interactions becomes important.

Regemorter \& Hoang Binh (1993) have discussed recently the important simplification of theory for solar Rydberg lines corresponding to the transitions between nearly degenerate states, where the differences of energy $E(n \ell, n \ell+1)$ are of the order of a few $\mathrm{cm}^{-1}$. These energy differences are much larger than the width so that the considered lines are isolated. They are however considerably smaller than the energy distances to the other perturbing levels $n^{\prime} \ell^{\prime}$ which may be neglected so that the Stark broadening problem corresponds to a simple three level close coupling system including $n \ell, n \ell+1$ atomic energy levels. In order to investigate such approximation, contributions (in angular frequency units) to the $\mathrm{Mg} \mathrm{I}$ $5 \mathrm{~g}^{1} \mathrm{G}-6 \mathrm{~h}^{1} \mathrm{H}$ line widths, due to different types of colli- sions, have been calculated as a function of the number of perturbing levels at an electron density of $10^{12} \mathrm{~cm}^{-3}$ and temperature of $5000 \mathrm{~K}$ and shown in Table 4. One can see that the inelastic collision contribution practically does not vary with the addition of new perturbing levels and that the variation of strong collision contribution is as well of the order of several percents. The elastic collision contribution has however a non negligible dependence on the perturbing level number. Since for solar Rydberg lines the elastic contribution to the width is for an order of magnitude smaller in comparison with other considered contributions, we may conclude that the approximation of Regemorter \& Hoang Binh (1993) is very good for Stark widths of the considered lines.

Table 4. Contribution of different types of collisions to the line widths (in angular frequency units) as a function of the number of perturbing levels of the initial level $(i)$ for $\mathrm{Mg} \mathrm{I}$ $5 \mathrm{~g}^{1} \mathrm{G}-6 \mathrm{~h}^{1} \mathrm{H}$ transition at an electron density of $10^{12} \mathrm{~cm}^{-3}$ for $T=5000 \mathrm{~K}$. Perturbing energy levels for the final level are $4 \mathrm{f}$, 5f, 6f, 7f, 6h, 7h, $8 \mathrm{~h}$

\begin{tabular}{|c|c|c|c|c|}
\hline $\begin{array}{l}\text { Perturbing } \\
\text { levels i' }\end{array}$ & $6 \mathrm{~g}$ & 69,71 & $5 g, 6 g, 71$ & $\begin{array}{l}5 g, 6 g, 79,8 g, \\
71,81,91\end{array}$ \\
\hline $\begin{array}{l}\text { coll. upper } \\
\text { level }\end{array}$ & $0.452(+9)$ & $0.456(+9)$ & $0.456(+9)$ & $0.456(+9)$ \\
\hline $\begin{array}{l}\text { coll. lower } \\
\text { level }\end{array}$ & $0.109(+9)$ & $0.109(+9)$ & $0.109(+9)$ & $0.109(+9)$ \\
\hline strong coll. & $0.119(+9)$ & $0.135(+9)$ & $0.128(+9)$ & $0.129(+9)$ \\
\hline elastic coll. & $0.368(+8)$ & $0.590(+8)$ & $0.468(+8)$ & $0.495(+8)$ \\
\hline
\end{tabular}

Since the elastic collisions have an important role for the Stark shift determination, for Stark shifts such approximation may become questionable.

In Table 5 our results (denoted as DSB) for Stark full widths for $\mathrm{Mg}$ I $5 \mathrm{~g}^{1} \mathrm{G}-6 \mathrm{~h}^{1} \mathrm{H}$ and $6 \mathrm{~g}^{1} \mathrm{G}-7 \mathrm{~h}^{1} \mathrm{H}$ transitions have been compared with results of Regemorter \& Hoang Binh (1993) (denoted as RHB), with calculation within the Griem's (1968) semiempirical approach of Carlsson et al. (1992) (denoted as GCRS) and with calculations of Chang \& Schoenfeld (1991) by using the Lindholm (1941) adiabatic theory (LCS). One can see that our calculations are in good agreement with the width calculations of Regemorter \& Hoang Binh (1993) while for shifts the differences due to the omission of perturbing levels with the different principal quantum number (as discussed concerning Table 4) exist. The agreement with adiabatic theory of Lindholm (1941) used by Chang \& Schoenfeld (1991), is apparently fortuitous for the width but shifts are largely overestimated, while the Griem's (1968) semiempirical approach, not appropriate for transitions between nearly degenerate states (GCRS), is in agreement with our results 
Table 5. Comparison of electron-impact width (W-FWHM) and shift $(d)$ values calculated according to various approaches, for $\mathrm{Mg} \mathrm{I} 5 \mathrm{~g}^{1} \mathrm{G}-6 \mathrm{~h}^{1} \mathrm{H}$ and $6 \mathrm{~g}^{1} \mathrm{G}-7 \mathrm{~h}^{1} \mathrm{H}$ transitions at an electron density of $10^{12} \mathrm{~cm}^{-3}$ for $T=5000 \mathrm{~K}$. The notation is: DSB - present calculations; RHB - Regemorter \& Hoang Binh (1993); GCRS - calculated by Carlson et al. (1992) by using the Griem's (1968) semiempirical formula with an effective Gaunt factor $g=0.5$; LCS - calculated by Chang \& Schoenfeld (1991) by using the Lindholm (1941) adiabatic theory

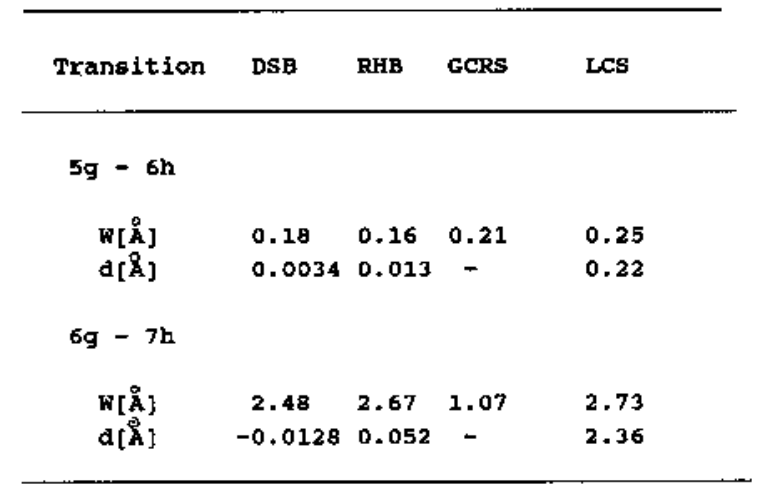

for $\mathrm{Mg} \mathrm{I} 5 \mathrm{~g}^{1} \mathrm{G}-6 \mathrm{~h}^{1} \mathrm{H}$ transition but gives more than two times smaller result for $6 \mathrm{~g}^{1} \mathrm{G}-7 \mathrm{~h}^{1} \mathrm{H}$ transition.

We hope that the comprehensive set of Stark broadening parameters of $\mathrm{Mg}$ I lines will enable the better use of Mg I spectral lines for solar plasma research.

Acknowledgements. This work is a part of the project "Physics and Dynamics of Celestial Bodies" supported by the Ministry for Science and Technology of Serbia.

\section{References}

Bashkin S., Stoner J.O. Jr., 1975, Atomic Energy Levels and Grotrian Diagrams, Vol. 1, North Holland, Amsterdam

Bates D.R., Damgaard A., 1949, Trans. Roy. Soc. London, ser. A 242, 101

Benett S.M., Griem H.R., 1971, Calculated Stark Broadening Paramaters for Isolated Spectral Lines from the Atoms Helium through Calcium and Cesium, Techn. Rep. No. 71-097, Univ. Maryland

Brault J., Noyes R.W., 1983, ApJ 269, L61
Brissaud A., Goldbach C., Leorat J., Mazure A., Nollez G., 1976, J. Phys. B 9, 1147

Butler K., Mendoza G., Zeippen C.J., 1993, J. Phys. B 26, 4409

Carlsson M., Rutten R.J., Shchukina N.G., 1992, A\&A 253, 567

Chang E.S., Avrett E.H., Manas P.J., Noyes R.W., Loeser R., 1991, ApJ 379, L79

Chang E.S., Noyes R.W., 1983, ApJ 275, L11

Chang E.S., Schoenfeld W.G., 1991, ApJ 383, 450

Cunto W., Mendoza C., Ochsenbein F., Zeippen C.J., 1993, A\&A 275, L5

Deming D., Boyle R.J., Jennings D.E., Widemann G., 1988, ApJ 333, 978

Deming D., Jennings D.E., Jefferies J., Lindsey C., 1991, In: The Solar Atmosphere and Interior, Cox A.N., Livingston W., Matthews M. (eds.). Univ. of Arizona Press, Tucson

Dimitrijević M.S., Konjević N., 1986, A\&A 163, 297

Dimitrijević M.S., Sahal-Bréchot S., 1984, JQSRT 31, 301

Dimitrijević M.S., Sahal-Bréchot S., Bommier V., 1991, A\&AS 89,581

Dimitrijević M.S., Sahal-Bréchot S., 1995, Phys. Scripta 52, 41

Edlen B., 1964, Handbuch der Physik 27. Springer, Berlin

Farmer C.B., Norton R.H., 1989, A High-Resolution Atlas of the Infrared Spectrum of the Sun and the Earth's Atmosphere from Space, NASA Ref. Publ. 1224, Vol. 1, Washington, Gov. Print. Office

Glenar D.A., Reuter D.C., Deming D., Chang E.S., 1988, ApJ 335, L35

Goldbach C., Nollez G., Plomdeur P., Zimmermann P., 1982, Phys. Rev. A 25, 2596

Griem H.R., 1968, Phys. Rev. 165, 258

Griem H.R., 1974, Spectral Line Broadening by Plasmas. Academic Press. New York and London

Helbig V., Kusch H.J., 1972, A\&A 20, 299

Jefferies J.T., 1991, ApJ 377, 337

Kusch H.J., Schweiker H., 1976, A\&A 53, 59

Lindholm E., 1941, Ark. Math. Astron. Fysik 28B, 3

Marasinghe P.A.B., Lovett R.J., 1986, Spectrochim. Acta B 41,349

Oertel G.K., Shomo L.P., 1968, ApJS 16, 175

Regemorter van H., Hoang Binh Dy, 1993, A\&A 277, 623

Sahal-Bréchot S., 1969a, A\&A 1, 91

Sahal-Bréchot S., 1969b, A\&A 2, 322

Sahal-Bréchot S., 1991, A\&A 245, 322

Waller I., 1926, Z. Phys. 38, 635 